\title{
Puppet theatre under Covid-19
}

\section{Cariad Astles and Emma Fisher}

Puppeteers; traditionally itinerant performers, and disseminators of political, religious, cultural and social information, have frequently needed to adapt their performances and tours to changing circumstances in relation to health. The Covid-19 pandemic and lockdown in many countries in 2020 led to the suspension of tours, performances, workshops and collaborations for thousands of puppeteers worldwide. As the weeks continued, however, puppeteers began to use the resources available to them to share material online, to make performances available and to address their work to the realities of the pandemic.

We have included here a sample of puppetry projects that are taking place around the world and some insights from puppeteers on how they are working through Covid-19; using puppetry to teach about Covid-19 and teaching puppetry in general; to entertain and to perform puppetry that is offered as ritual at a time of crisis. This work shows the resilience of puppetry during a world pandemic to thrive, to teach, to entertain and to heal.

\section{Teaching about Covid-19 through Puppetry}

In Canada, a puppet raven known as Kahkakiw in Cree delivers information about Covid-19 in Cree to indigenous communities. Commissioned by Professor Steph McLachlan from the Department of Environment and Geography at the University of Manitoba, McLachlan worked with a first nation puppeteer, Samson Hunter, translator Phyllis Hart and elders from the community, to create a film that fused health information and Cree culture together to better inform communities about how to keep yourself and others safe during the pandemic, as well as providing information and humour.

The Raven was chosen specifically, as within Cree culture it is known 'as an environmental protector and cleaner' (Phyllis Hart cited in Pauls 2020). Hart noted (Stranger, 2020) that Cree is a spiritual language $\div$ Tthe raven is a spiritual character in Cree culture and masks and puppets have been long used amongst first nation people for ritual ceremonies. The Raven puppet speaks in Cree and serves as both a way to inform about Covid-19 within the Cree culture while preserving the Cree language and culture. 
Similarly, in Tamil Nadu in India, puppeteer Mu Kalaivanan is using traditional puppetry to highlight fake news about coronavirus and using puppets to teach about how best to stop its spread. Kalaivanan has been a puppeteer for the last 44 years. The message he is sending through his puppets is to stay at home during lockdown and to not listen to fake news about cures that have not yet been found. Kalaivanan has worked with many NGOs over the years to use puppetry to teach about what is going on in the world, for example about global warming and women's rights. Kalaivanan's belief is that children learn better when being taught by a puppet. This practice follows the tradition of using puppets in many communities throughout the world, to share healthcare messages, with the belief that the puppet is a better communicator of messages than a human. This can be attributed to its visual impact, the humour in many puppet shows, and the fact that people are being entertained rather than lectured to.

Kathy Foley, a US-based scholar of Indonesian puppetry, explores whether puppetry can be considered a cure. In her article 'Can puppetry be a cure in a time of crisis?', Foley discusses the work of Indonesian puppeteer and Dalang, Purbo Asmoro. In Indonesia, a Dalang is a puppeteer leading a Wayang (traditional Indonesian puppetry) performance. Purbo Asmoro uses the ancient art of Wayang to respond to Covid-19. The normal practice in Indonesian puppetry is for performances to be delivered via a troupe of multiple puppeteers, musicians and audience. Due to lockdown, however, Asmoro is performing solo as both puppeteer and musician, and live streams his performance. He performs a 'Ruwatan' ('Safe Making') performance of the 'Sudamala' story.' (Foley, 2020) The word Ruwatan comes from the word Ruwat which means 'to cleanse'. The Ruwatan ceremony has been told through shadow puppetry since 1630 :

A ruwatan ceremony involves a sacred wayang kulit (shadow puppet) play that is performed as a form of exorcism for people (sukerta) who have fallen victim to personal disaster and are considered magically vulnerable to the evil god Bathara Kala. (Susilo, 2000, p. i)

This kind of puppet performance is called 'doa untuk dunia' ('prayer for the world') and is performed to cleanse and to perform 'ritual healing through puppetry' (Foley, 2020) at a time of the Covid-19 crises. 


\section{Teaching Puppetry During Covid-19}

As universities, colleges and schools have closed during lockdown around the world, educators in puppetry training have had to become resourceful. Puppetry is a very tactile, somatic art form, which often involves educators teaching by example and trainee puppeteers working in close physical communication with each other: breathing together, working together on a single puppet and responding to each other's impulses, movements, and so on. This has increasingly been the case over the last twenty to thirty years, with a general move away from the solo puppeteer in performance, towards ensemble puppetry with collectively animated figures. Educators around the world have therefore had to become very resourceful in creating training videos, teaching online with their students and re-examining how to teach the art of puppetry.

Cariad Astles organised two large international gatherings of puppetry educators in May and June 2020, to share ideas, tools and techniques; and to talk about how to collaborate and share resources. Astles put to the group two questions:

1. Which specific aspects or practices of teaching puppetry performance online are possible? How?

2. Would it be possible for some of your performance classes to be shared 'live', online, with other teachers/trainers and students? Which ones, where and when? What opportunities do we have for collaboration?

As we write, these sessions are ongoing, but initial discussions and findings suggest that, while the co-presence of other puppeteers in the same space causes limitations in approach, aspects of puppetry performance can be taught online, such as an increased focus on detail; the close relationship between the puppeteer and puppet, as a changing dynamic; using the frame of the screen as puppet booth; puppet shows for one, such as Lambe Lambe performance, a Brazilian form of puppetry as microtheatre, for one person only; shoebox and suitcase performance (shows created in a suitcase or shoebox for very small audiences); targeted work for individuals and small groups. Other opportunities that arose through the discussions included the question of accessibility for people in other parts of the world, who could participate in classes (internet connections dependent); using the demands of online work to progress an emancipatory dynamic where students are more likely to learn from each 
other and the teacher facilitates their own experience and creative journey, and the creation of theatre of the everyday, such as object theatre, by using only objects students can find around them, in their immediate surroundings. Other potential areas raised included using the house as museum, to investigate the history and narrative of objects at home; celebrating poor theatre; creating 'front-yard' theatre, huge puppets (so as to be socially distanced from each other with the intermediary of a giant puppet in between); exploring the function of the puppet in an uncertain world, and creating online festivals of work. What is exciting about all these proposals and tests is the idea that the puppeteer has to revert to creative and flexible means in order to try out and share their art. After the popularity of multi-operated puppets and ensemble puppetry performance over the last twenty years or so, perhaps the solo puppeteer will return, with a closer and more personal relationship with the objects around herself/himself.

\section{Testimonies from puppeteers creating work under Covid-19}

We asked puppeteers around the world the question: 'how are you working as a puppeteer through the Covid-19 crisis?', Kay Yasugi (from Australia) and Niamh Lawlor (from Ireland) talk below about the impact it has had on them, and how they are continuing to work.

\section{Kay Yasugi}

It has been a challenging few months in Australia, with bushfires in January, floods in February and a global pandemic since March. The Conavirus pandemic has affected all of us, with many artists (including myself) losing gigs and other work. We are all experiencing unprecedented change in the way we live. Now, more than ever, we need to be finding ways to build our community and help each other feel connected.

I have been quite involved with UNIMA Australia in our efforts to offer additional support to artists. There have been more frequent mailouts, including information on helping artists who have lost work due to Covid-19, as well as links to online shows and other resources. We have also organised Zoom meetings with UNIMA members, with 'think tanks' (discussing how to create work online) as well as more relaxed maker sessions. More Zoom meet-ups are planned for the future, including 'Puppet Doctor' sessions (inviting expert puppet makers to give advice on your puppet ailments - whether it be mech malfunctions or a puppet hip replacement). We recently held a meeting to start planning the $50^{\text {th }}$ Anniversary of UNIMA 
Australia, which will involve a puppet film project (with the theme of 'Silver Linings'), an online Zoom celebration and a special digital edition of our magazine, UNIMA Oz. In relation to my own work, I am currently a participating artist for the Creative Leadership in Learning 2020 Program with the Sydney Opera House. This involves working with a primary school in Sydney over 20 weeks to create and devise a puppetry performance. Due to Covid-19, our first few sessions were run entirely online via Zoom. More recently I have been allowed to visit the school on site, as government restrictions were lifted for schools in New South Wales and all students returned to school on $25^{\text {th }}$ May 2020. I have also been working as an English language teacher at another primary school in Sydney (mainly creating remote learning resources online and now teaching back in school).

So, to answer your question, I am not technically working as a puppeteer during this time. However, I am channeling my energy into supporting and connecting with other artists, running puppetry workshops for children and using puppetry in my own teaching at school. I have been amazed by the opportunities that have arisen from this situation, where I have been able to attend international workshops (through Zoom) without leaving my own home. I am so touched by the kindness and generosity of artists around the world who are sharing their skills and their craft so that we can keep creating during this time. A puppetry colleague, Leon Hendroff, designs Christmas windows every year for a retail store in Western Australia called Remedy, and the first display he made was based on the theme 'After Every Winter Comes a Spring'. I have been reminded of this encouraging thought as we enter winter here in Australia. Despite it all, I know that spring is coming.

\section{Niamh Lawlor}

Niamh Lawlor from Púca Puppets in Ireland was just setting up her set for a new show she was developing for a residency when lockdown happened and she could no longer carry on her residency. She was disappointed but sought out new ways to create new work. She started developing new work with a musician remotely, creating workshops as both films and for live virtual sessions. She also used this as a way to connect with her nieces and nephews, sending them puppet-making parcels and how-to films. Niamh whose niece had asthma prepared her parcels with a mask on and clean hands and she did not posted the parcel for 72 hours after it had been packed up to make sure it would not transmit any germs. (It was these Iposted, leaving one to a niece with asthmath for 72 hours before doing so, for now I will deliver the pop up props because we use fresh items like oranges, but no owrry if you do not 
Niamh is one of three performers that work on a show by the company Helium Arts, Pop-up Picnic. This show was due to be performed during lockdown but was cancelled. Pop-Up Picnic sends puppeteer Niamh Lawlor, musician Thomas Johnston and actor Roseanne Lynch into homes of early years' children with complex needs to perform a multi-sensory performance that incorporates object manipulation and music. Their aim is to provide parents with new ways of bonding with their young child. They are now working with Pop-up Picnic director Joanna Williams to bring the show to the children and their parents or earerscarers via virtual means. Usually the performers would arrive with a picnic basket and rug that they would set up on the floor transforming the domestic world of the living room into an outdoor space where they were having a picnic; however, during Covid-19 this is not possible, so instead, they send the parent or earercarer a picnic basket in the post, ahead of the performance. They are very aware that they are working with children in a high risk category and so they prepare the baskets with masks on and clean hands (and they are not posted for 72 hours after they have been packed up) to make sure they won't transmit any germs. The parents at home, or the carer in the hospitalpice, isare prompted when to take out a specific object.

One of the objectives of the project is to introduce the family to new ways to play and to stimulate the child: things like oranges, sponges, water and things they have access to in their daily lives. As such, they feel that the virtual performance can still be multi-sensory for the child while informing the parent or earriercarer about new ways to interact and play with the child.

\section{Conclusion}

This report touches on just a handful of puppeteers creating work under the Covid-19 pandemic in 2020. It is likely that as things change and move in relation to the pandemic, puppeteers will also find new ways of performing and communicating. Ironically, the links between health and puppets are closer than ever before. Where puppeteers working in hospitals were previously used to having only 'wipe-clean' puppets, now hygiene, appropriate distancing and clear healthcare information have become the norm for all puppeteers. Puppetry, however, as noted within this journal volume, functions as a mediator and to communicate complex information. The future of puppetry in relation to health, 
wellbeing and disability following the Covid-19 international crisis will be interesting to follow.

\section{References}

Edex Live, (2020) ' TN artist takes to puppetry to spread awareness on COVID-19, https://www.edexlive.com/news/2020/apr/12/tn-artists-takes-to-puppetry-tospread- $\quad$ awareness-on-covid-19-11263.html Accessed 31 May 2020.

Foley, Kathy. (2020), 'Puppetry In a Time of Coronavirus: Purbo Asmoro Curing the World Via Puppetry' UNIMA USA, http://www.unimausa.org/blog/2020/4/1/puppetry-in-a- time-of-coronavirus-purbo-asmoro-curingthe-world-via-puppetry Accessed 28 May_2020.

Muralidharan, Kavitha. (2018), 'Bommalattam: How Kalaivanan is keeping an ancient form of puppetry alive through political messages' First Post, https://www.firstpost.com/living/bommalattam-how-kalaivanan-is-keeping-anancient-form-of-puppetry-alive-through-political-messages-4485549.html Accessed 31 May 2020.

Pauls, Karen. (2020). Cree-speaking raven puppet gives COVID-19 health information https://www.cbc.ca/news/canada/manitoba/covid-health-information-cree-raven1.5528099 Accessed 29 May 2020.

Stranger, Darrell. (2020), 'Cree-speaking raven puppet helps spread COVID-19 awareness, ABTN National News, https://www.aptnnews.ca/national-news/cree-speakingraven- puppet-helps-spread-covid-19-awareness/ Accessed 30 May 2020.

Susilo, Joko. (2000), 'A musical ethnography of the Ruwatan performance in Central Java : tradition and change' (Thesis, Ph. D.). http://hdl.handle.net/10523/6799 Accessed 1 June 2020.

\section{Contributor details}

Cariad Astles is Course Leader for the BA Puppetry at the Royal Central School of Speech and Drama and is also Lecturer in Drama at the University of Exeter, UK. She is President of 
the Research Commission for the international puppetry association, the Union Internationale de la Marionnette. Cariad specialises in training, researching, performing and directing for puppet theatre; in objects and puppets within healthcare and applied settings and in the puppet as marker of political and cultural identity. She frequently runs training workshops in the UK and overseas, most recently in China, Chile, Australia, Germany, France and Spain.

Contact: Royal Central School of Speech and Drama, Eton Avenue, London NW3 3HY, UK.

Email: c.astles@cssd.ac.uk; c.astles@exeter.ac.uk

Orcid: 0000-0001-6327-8980

Emma Fisher is a researcher, puppeteer, theatre designer, playwright and educator. She completed her $\mathrm{PhD}$ in puppetry and disability in 2018 at Mary Immaculate College. Emma's research explores unconventionally constructed puppets that reflect the disabled body. She is President of Irish UNIMA (the world puppetry organisation), on the working group of the UNIMA Research Commission and co-organiser of the Broken Puppet Symposia. She founded Beyond the Bark, an inclusive puppet and installation theatre, in 2007. Emma teaches puppetry at Mary Immaculate College and is guest lecturer at Limerick Art College, the London School of Puppetry and The World Academy of Music and Dance, UL.

Contact: beyondthebarktheatre@gmail.com

Orcid: 0000-0003-0163-397X

Kay Yasugi is a puppeteer, teacher, workshop leader, and is currently president of UNIMA Australia. She is based in Sydney, Australia, and runs a company called Pupperoos. She has a professional puppetry diploma from the London School of Puppetry and is a trained primary school teacher. She creates and develops workshop and educational activities using puppetry, as well as making and performing shows and touring to puppetry festivals.

Contact: info@pupperoos.com

Niamh Lawlor is a visual, film, participative and theatre artist working primarily through the medium of puppetry or object animation. Trading as Púca Puppets since 1997 she has a Master of Directing for Theatre from Hull University and an Honours degree in Visual 


\section{Communication from the National College of Art and Design.}

\section{Contact:niamh@pucapuppets.com}

